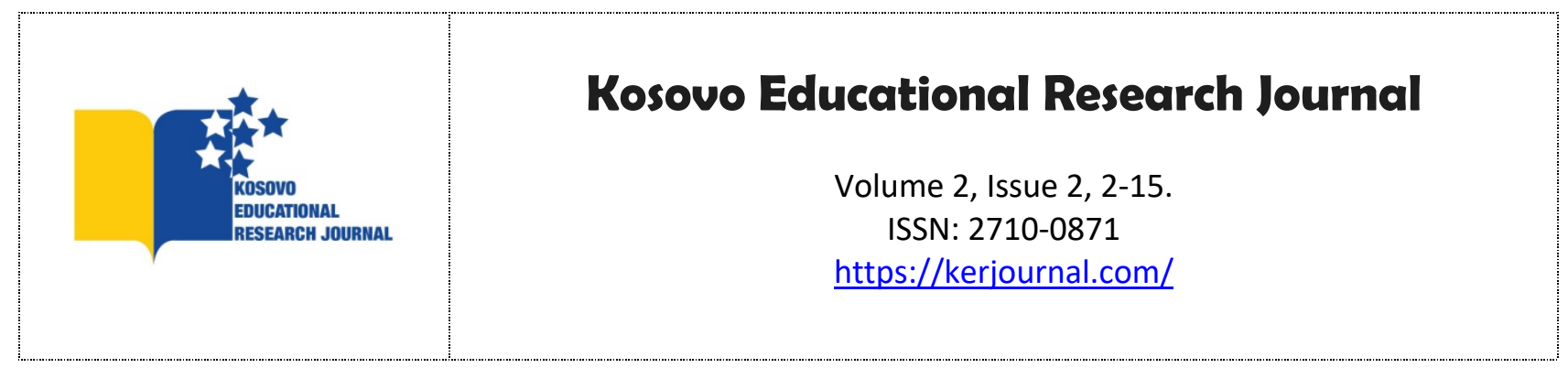

\title{
Loja në natyrë me fëmijët me sindromën Down dhe sensibilizimi i tyre për të mirat mjedisore
}

Fatmire Pulaj ${ }^{1}$

Prof. Asoc. Dr. Rifat MORINA²

\begin{abstract}
Abstrakti: Le të jetë ky punim një thirrje për shpresë për ne të rinjët, por edhe për mësimdhënësit sidomos për ata mësimdhënës që nuk kanë pasur përvoja me fëmijë me nevoja të vecanta.

Puna dhe dashuria janë nismë dhe celës të cdo gjëje, e nëpërmjet tyre ne duhet të hapim dyert e pranimit dhe arsimimit për këta fëmijë.

Barazia, duhet të jetë në qëllimet themelore të edukatës sonë, ku secili njeri pavarësisht specifikave të ndryshme, të identifikohet special dhe unik. Kjo duhet të jetë e njejtë si për ne, një lloj edhe për këta fëmijë... ata janë si ne dhe ne jemi si ata.

Bazuar në këto u përcaktua edhe qëllimi i këtij punimi : "Loja në natyrë me fëmijët me sindromën Down dhe sensibilizimi i tyre për të mirat mjedisore", që përmes kësaj teme ti shohim më afër karakteristikat e vecantit e këtyre fëmijëve.

Për kompletimin e punimit është përdorur Metoda e Analizës Teorike duke bërë një vështrim të përgjithshëm të literaturave në lidhje me temën.
\end{abstract}

Fjalët kyçe: Sindroma Down, prindërit, arsimimi, pavarësi personale, loja, loja në natyrë, sensibilizimi

To cite this article: Pulaj, F \& Morina, R. (2021). Loja në natyrë me fëmijët me sindromën Down dhe sensibilizimi i tyre për të mirat mjedisore. Kosovo Educational Research Journal, 2(2), 2-15

\footnotetext{
${ }^{1}$ University of Prizren "Ukshin Hoti”, Faculty of Education (Student)

${ }^{2}$ University of Prizren "Ukshin Hoti”, Faculty of Education (professor)
} 


\begin{abstract}
Let this diploma thesis be a call for hope to us ( young people ), but also for teachers especially for those teachers who did not have experiences with children with special needs. Work and love are the initiative and the key to everything, and through them we must open the doors of acceptance and education for these children.

Equality should be in the basic goals of our education, where each person despite the different specifics, to be identified special and unique. This should be the same for us, and same for these children too ... they are like us and we are like them.

Based on these, the purpose of this diploma thesis was determined: "Outdoor play with children with Down syndrome and their awareness of environmental benefits", so that through this topic we can see more closely the special characteristics of these children.

The Theoretical Analysis Method was used to complete the diploma thesis by making an overview of the literature related to the topic.
\end{abstract}

Keywords: Down Syndrome, parents, education, personal independence, play, outdoor play, awareness

\title{
Hyrje
}

"Dashuria nuk llogarit kromozomet"

Secili fëmijë që nga momenti i lindjes duhet të jetë unik. Edhe fëmijët me Sindomë Down janë pothuajse sikur gjithë fëmijët e tjerë kur lindin, në fakt janë unik si gjithe fëmijët e tjerë të botës.

Fëmijët ( personat ) me Sindromë Down mund të gëzojnë një jetë të gjatë. Edhe pse ende është një lloj miti ku thuhet se personat me Sindromë Down e kanë të vështirë për të arritur qëllime në jetë, por realiteti është se ata me mbështetjen e duhur, mund të arrijnë të gjitha qëllimet që duan t'i realizojnë. Në fakt, shumica e personave me Sindromë Down mësojnë të flasin, të ecin dhe shumë prej tyre edhe arsimohen dhe bëjnë një jetë të plotësuar e janë shumë të dashur me njerëzit duke mos harruar se janë shumë social e në vecanti duan lojën.

Jeta e një fëmije nuk mund të konceptohet pa lojën dhe imagjinatën, kjo është një lloj edhe për fëmijët me sindromë Down.

Për këtë loja na tregon shumë rreth zhvillimit të një fëmije, temperamentit të tij, dinamikave familjare dhe mënyrës se si ai percepton botën që e rrethon. Në fakt loja ndihmon kujdestarët, 
prindërit, terapistët të krijojnë një marëdhënie besimi me fëmijën duke iu përshtatur gjuhës së tij. Mos harroni, se duke luajtur me fëmijën tuaj do mësoni shumë se si ai e ka kaluar ditën ( nëse janë të regjistruar në ndonjë qendër edukimi ), do i mësoni atij të përballet me situata të cilat ndoshta nuk i has në jetën e përditshme, do i prezantoni një botë të madhe në dhomën e tij të vogël.

\section{Kapitulli I}

\section{1. Çka është sindroma Down?}

Down - për nder të Dr.Langdon Down që njohu i pari karakteristikat dalluese të sindromës Down. Sindromi - një koleksion i karakteristikave dalluese ose simptoma (Cunnigham, 2006) ${ }^{3}$

Sindroma Down është një rregull kromozomik që ndodh natyrshëm dhe që gjithmonë ka qenë pjesë e gjendjës njerëzore, duke qenë universalisht i pranishëm në të gjitha linjat racore,gjinore ose socio-ekonomike (Ramachadran, 2010) ${ }^{4}$

Njeriu e ka trupin e përbër nga qelizat. Ku cdo qelizë në trupin e njeriut ka 46 kromozome, 23 kromozome të trashëguara nga njëri prind dhe 23 të tjera të trashëguara nga tjetri prind.Tek rasti sindromës Down, në ciftin e 21-të bashkangjitet një kromozom shtesë si pasojë e një ndarje anormale qelizore dhe si rezultat personi ka 47 kromozome në cdo qelizë ose në një pjesë të qelizave të trupit të tij $(B, 2012)^{5}$

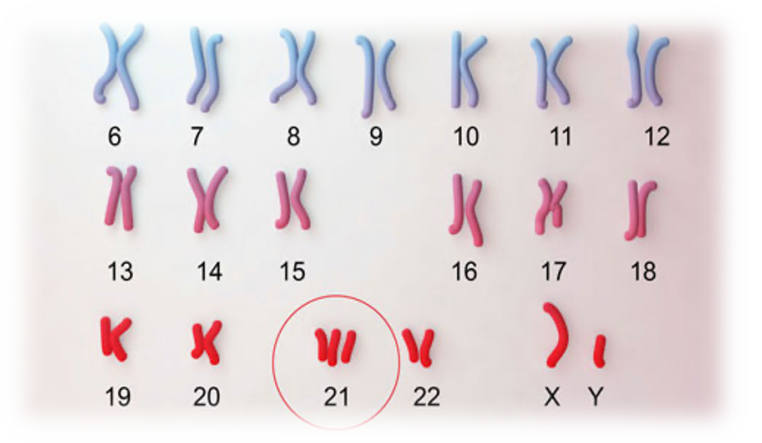

Figura 1. Ndryshimi i kromozomeve cifti 21

\footnotetext{
${ }^{3}$ Cliff Cunninham, Third edition revised and expanded Down Syndrome an introduction for parent and carers, (faqe 13)

${ }^{4}$ Dr.Surekha Ramachadran,The Down's Syndrome handbook,(faqe 4)

${ }^{5}$ Bajraktari B, Halili, A.Gashi A.,2012. Biologjia 12. Prishtinë
} 


\subsection{Shkathtësitë e Vetëndihmës dhe Pavarësia.}

Të gjitha këto janë testuar në qendër dhe mos harroni se çdo fëmijë është një individ unik.

Tabela 1. Aftësitë e vetë-ndihmës tek fëmijët

\begin{tabular}{|l|l|l|}
\hline & Fëmijt me DS & Fëmijët e tjerë \\
\hline $\begin{array}{l}\text { Buzëqeshja e përgjegjshme ( } \\
\text { e pavetëdijshme })\end{array}$ & $1.5-5$ muaj & $1-3$ muaj \\
\hline Thithja e gishtave & $10-24$ muaj & $7-14$ muaj \\
\hline $\begin{array}{l}\text { Pije nga kupa ( e pa } \\
\text { ndihmuar) }\end{array}$ & $12-32$ muaj & $9-17$ muaj \\
\hline Përdor lugën & $13-39$ muaj & $12-20$ muaj \\
\hline Kontrollon pijatën & $2-7$ vjec & $16-42$ muaj \\
\hline Veshet vetë ( pa e ndihmuar ) & $3.5-8.5$ vjec & $3.25-5$ vjec \\
\hline
\end{tabular}

(Ramachadran, 2010)

Tabela 2. Hapat e parë të pavarësisë personale

\begin{tabular}{|l|l|}
\cline { 2 - 2 } \multicolumn{1}{l|}{ Ushqimet } & Fëmijët me SD \\
\hline Ushqen vetën me biskota & 10 muaj \\
\hline Pi nga gota & 20 muaj \\
\hline Përdor lugë e pirun & 20 muaj \\
\hline Mund të bëjë sandëich & $50 \%$ në $11-20$ vjec \\
\hline Mund të bëjë një kafe / caj & $46 \%$ në $11-20$ vjec \\
\hline Mund të përdor mikrovalin & $24 \%$ në $11-20$ vjec \\
\hline Mund të përkulet dhe pastrojë tavolinën & $80 \%$ në $11-20$ vjec \\
\hline Mund të ha në restorant & $100 \%$ në $11-20$ vjec \\
\hline
\end{tabular}

(Ramachadran, 2010)

\begin{tabular}{|l|l|}
\cline { 2 - 2 } \multicolumn{1}{l|}{ Tualeti } & Fëmijët me SD \\
\hline I thatë gjatë ditës ( nuk urinon rrobat) & 36 muaj \\
\hline Kontrollon kohen e urinimit & 36 muaj \\
\hline
\end{tabular}




\begin{tabular}{|l|l|}
\hline I thatë gjatë natës ( nuk urinon rrobat) & $60 \%$ në $7-14$ vjec \\
\hline Përdor tuletin pa e ndihmuar & $4-5$ vjec \\
\hline Plotësisht i vetëdijshëm, ditën dhe natën & $98 \%$ në $11-20$ vjec \\
\hline Lahet pa e ndihmuar & $60 \%$ në $12-20$ vjec \\
\hline Mund të kreh flokët e të tjerëve & $95 \%$ në $8-14$ vjec \\
\hline Mund të kreh flokët e veta & $45 \%$ në $12-20$ vjec \\
\hline Mund të lajë flokët & $34 \%$ në $14-22$ vjec \\
\hline Mund të bëjë tush & $50 \%$ në $12-20$ vjec \\
\hline Mund të prej thonjët e duarve dhe këmbëve & $9 \%$ në $16-24$ vjec \\
\hline
\end{tabular}

Aftësitë motorike

\section{Ecë vetë}

Ngjit / zbret shkallët pa ndihmë

Mund të ngasë bicikletën

Mund të hedhë dhe të kapë një top
Fëmijët me SD

23 muaj

81 muaj

$35 \%$ në $11-20$ vjec

$98 \%$ në 11- 20 vjec

Veshja dhe Aftësit praktike / sociale

\begin{tabular}{|l|l|}
\hline Veshet pjesërisht & $4-5$ vjec \\
\hline Veshet pa ndihmë & $80 \%$ në $11-20$ vjec \\
\hline Zgjedh rrobat e duhura & $70 \%$ në $11-20$ vjec \\
\hline
\end{tabular}

\begin{tabular}{|l|l|}
\hline Mund të tregoj kohën & $20 \%$ në $11-20$ vjec \\
\hline Mund të numërojë shuma të thjeshta parash & $40 \%$ në $11-20$ vjec \\
\hline Mund të shkoj në dyqan vetëm & $26 \%$ në $11-20$ vjec \\
\hline Kalon rrugën vetëm & $40 \%$ në $11-20$ vjec \\
\hline
\end{tabular}

(Dr.Surekha Ramachadran, 2010)

\section{Kapitulli II}

\subsection{Loja në natyrë}


“E vërtetë, më shumë se sa të jenë të zgjuar dhe të bashkëveprojnë me të tjerët, prindërit duan që fëmijët e tyre të jenë të lumtur” (Burdette, 2005) ${ }^{6}$

Çdo gjë mund të konsiderohet si pjesë e natyrës nëse ajo pjesë është mjedis i jashtëm. Mjediset e jashtme njihen si vende të hapura që ndryshojnë vazhdimisht e sidomos fëmijët ndihen të lirë, të zhvillojnë aftësitë fizike pasi mund të vrapojnë, hidhen dhe të jenë në kontakt me elementët e natyrës. Ku duke luajtur në mjedise të jashtme fëmijët përfitojnë prej rrezeve të diellit, elementëve të natyrës dhe ajrit te pastër të cilët kanë ndikim të rëndësishëm në zhvillimin e mushkërive, rritjen e imunitetit etj (Çeça, 2019)

Tërë këto elemente të lartë përmendura duken normale për fëmijët që kanë një zhvillim normal, por nga këto dalin edhe nënpyetje se a vlejnë tërë këto edhe për fëmijët më sindromë Down. E nga studimet ne marrim përgjigje interesante... se fëmijët si me dhe pa sindromë Down së pari janë fëmijë si të gjithë fëmijët, e nga kjo ata shpjegojnë që fëmijët me sindromë Down kanë benifitet e njejta nga ekspozimi në natyrë, pastaj nga loja apo cfarë do aktiviteti tjetër në mjediset në natyrë. Por, pse aktivitetet në natyrë me fëmijët më sindromë Down janë të pakta?, edhe për këtë studiuesit na japin disa përgjigje: (Çeça, 2019)

1. Frika ndaj aksidenteve të mundshme, kështu prindërit tentojn t'i mbajnë fëmijët e tyre të mbyllur pasi kështu ata i kanë nënkontrollë. Këto frikëra lidhen me një keqinterpretim të realitetit, pa patur zakonisht një ndikim të qënësishëm në shoqëri (Çeça, 2019)

2. Tjetër një arsye lidhet me faktin se shumica e prindërve punojnë gjatë pjesës më të madhe të ditës dhe për këtë ata tentojnë t'i regjistrojnë fëmijët e tyre në qendra edukimi. Në këtë mënyrë kohës gjatë të cilës fëmijët mund të kalojnë kohë nën përkujdesjen ë prindërve dhe të zhvillojn një lojë në natyrë i’a kanë zënë vendin aktivitetet brenda qendrës ku ata janë të regjistruar (Çeça, 2019)

3. Po, ashtu studime të ndryshme kanë vënë re se gjatë stinëve të ndryshme p.sh, gjatë periudhës së dimrit fëmijët nuk lejohen të luajnë jashtë, kjo për shkakë të frikës se mos sëmurën ose ftohen. Por nëse mendoni se duke evituar mjediset e hapura fëmija juaj do të sëmuret më rrallë, ky është një mendim i gabuar, e ka më shumë gjasa që fëmijët të

\footnotetext{
${ }^{6}$ Burdette, Resurrecting free play in young children looking beyond fitness and fatness to attention, affiliation, and affect. Archives of Paediatrics and Adolescent Medicine, 159, ( faqe 46-50)
} 
sëmuren kur qëndrojnë në ambiente të mbyllura kjo pasi hapësira fizike është më e vogël dhe nga ajri i ndenjur ka pasoja për shëndetin e fëmijës (Çeça, 2019) ${ }^{7}$

Secili fëmijë duhet të luaj të paktën 40 minuta në ditë në natyrë, pasi kjo gjë është jetike për të gjithë fëmijët si me apo pa sindromë Doën.. pra për të gjithë pa përjashtim (Çeça, 2019)

Natyra ose mjedisi i jashtëm ofron shumë stimuj që tërheqin vëmendjen dhe interesin e fëmijëve. Shkopinjt, gurë, lulet, gjethet, dheu, bari eksplorohen me kuriozitet nga fëmija dhe nxisin të mesuarin për sa kohë fëmija i përdor ato për të luajtur. Të gjitha elementët e natyrës u përgjigjen nevojave dhe imagjinatës së fëmijëve, në këtë mënyrë ata mund tu japin objekteve kuptime të reja dhe të ndryshme në të njëjtën kohë p.sh një shkop mund të përdoret si një varkë, një gjethe si pjatë etj. Kjo do çojë më vonë në zhvillimin e aftësive kreative, në zgjidhjen e problemeve, dhe bashkëveprimin me të tjerë. Mbi të gjitha ju nuk duhet të shpenzoni për këto objekte, pasi ato gjenden kudo në natyre dhe nuk kanë limitet që kanë objektet komerciale. Pra, eksplorimi i elementëve të natyrës është gjithashtu i rëndësishëm për të tërhequr vëmendjen e fëmijëve ndaj pasurive dhe diversitetit natyror. Ndjenja e eksplorimit dhe magjepsja ndikojnë në proçesin e të mësuarit dhe nxisin zhvillimin e lidhjeve emocionale përkundrejt mjedisit. Përmes lojës në mjedise të hapura dhe eksplorimit të elementëve të natyrës, do të jetë e mundur të promovojmë edukimin në kuptimin e plotë të fjalës. Pjesë interesante është edhe kontakti me ujin ose dheun, pasi sipas kërkuesve ka një impakt pozitiv në rritjen e imunitetit të fëmijëve (Çeça, 2019)

Këto studime të thella e me vlerë të madhe vlen të cekët se deri diku kanë impakt të njejtë edhe tek fëmijët me sindromë Down, po është normalë që tek këta fëmijë vlera ndryshon varësisht nga gjendja e fëmijës.

Kur fëmijët zhvillojn lojë në natyrë i rrituri mund të qëndrojë në distancë dhe të vëzhgojë fëmijën duke e lënë të lirë të eksplorojë mjedisin përreth. Si të rritur duhet tu sigurojmë fëmijëve mjetet dhe hapsirën e nevojshme. Loja në mjedise i jep mundësi fëmijës të zhvillojë një numër të madhë aftësishë si në zgjidhjen e problemeve, vetë- besim, këmbëngulje, vetë-angazhim dhe të njohë më mirë veten. Gjatë lojës fëmija duhet ti jepet mundësia të dështojë ose të ketë sukses duke mësuar nga gabimet dhe arritjet. Nëse ne do të parandalojmë të gjitha situatat p.sh pak më të lehta apo ndonjëherë ndonje situatë e rrezikshme atëher fëmijët në një moshë më të rritur nuk do dinë si të reagojnë në situata të paparashikuara dhe do kenë më pak konfidenc në përballjen

\footnotetext{
${ }^{7}$ Msc. Albana Xhemali dhe Msc. Jonida Çeça - FËMIJËT dhe LOJA, 2019 - Tiranë
} 
e tyre në mënyrë të pavarur. Mjedisi i jashtëm na ofron shumë mundësi që fëmijët të tregojnë cilësi të personalitetit të tyre dhe aftësi të cilat nuk shafqen në mjediset e brendshme (Maynard $\mathrm{T}, 2013)^{8}$

Vetë- besim, këmbëngulje, vetë-angazhim dhe të njohë më mirë veten, ishin disa nga pikat kryesore që u cekën më lartë... e këto pika duhet të zhvillohen edhe tek fëmijët me sindromë Down, pasi janë pika konkrete që bënë që fëmijët me sindromë Down të gjejnë pavarësinë personale si dhe të ndihet pastaj i pranuar nga rrethi (Çeça, 2019)

E Nëse doni që të përfshiheni në lojën e fëmijës tuaj duhet të keni në konsiderat dy gjëra:

- Fëmija juaj duhet t'jua lejojë këtë gjë. Çka do të thotë që është fëmija juaj që ju fton të luani me të dhe hyrja juaj në lojë nuk duhet të bëhet ne mënyrë intruzive.

- Rregullat dhe rolin tuaj në lojën e fëmijës e përcakton vetë ai. I rrituri në lojën e fëmijës duhet të qëndrojë në një rol pasiv dhe të presë që fëmija ti tregojë atij se çfarë duhet të bëjë (Çeça, 2019)

Në këtë vazhdim do të flasim pak më konkret rreth temës ose thënë më saktësisht për lojën e fëmijët me sindromë Down në natyrë.

Fëmijët me sindromë Doën përfshihen më rrallë në lojë krahasuar me fëmijët e tjerë. Ata kanë nevojë për mbështetjen e specialistëve që të mësojnë përmes lojës, varesisht nga gjendja e fëmijës. Shpesh na lind pyetja: "A luajnë fëmijët me sindromë Down ndyshe nga fëmijët e tjerë?". Studime të ndryshme dhe analiza të specialistëve kanë treguar se fëmijët me sindromë Down luajnë ndryshe nga fëmijët me tjerë. Edhe pse thuhet se "të gjithë fëmijët mund të luajnë". Por, kjo vije si pasojë nga stadi ku një fëmijë më sindromë Down gjendet (Çeça, 2019)

Fëmijët me sindromë Down kanë shumë përfitime nga lojrat aktive dhe ato janë të shumta. Lojrat aktive jo vetëm që ndikojnë në mirëqënien fizike të fëmijës, por gjithashtu ndikojnë në zhvillimin e tij mendor. Duke luajtur me fëmijën tuaj ju do të jeni në gjendje ti mësoni atij disa aftësi por duhet të dimë se ai ka nevojë për ndihmën tuaj gjatë lojës. Më poshtë do të listjmë disa lojra që ju mund të zhvilloni me fëmijët tuaj në natyrë(Çeça, 2019)

Duhet të organizoni sa më shumë aktivitete me ujë, rërë, baltë etj. Stimuloni fëmijën të prek objektet në mjedisin e jashtëm si gjethet, barin, gurët etj. E gjatë aktiviteteve flitini fëmijës rreth

\footnotetext{
${ }^{8}$ Maynard T, Waters J, Clement J. "Moving outdoors: furtherexplorations of "child-initiated" learning in the outdoor envi-ronment. Education" 3-13. 2013; 41:282-99.
} 
objekteve që ata po eksplorojnë duke i emërtuar ato. Edhe pse do ju duket se fëmija nuk po ju ndjek dhe ndoshta nuk po ju kupton ju vazhdoni ta bëni këtë gjë. Zhvilloni gjithashtu lojra me top ata e duanë shumë këtë gjë (Çeça, 2019).

Sugjerim për prindërit... mos prisni që fëmija juaj të jetë ai që fillon lojën ose të përfshihet vet në lojë, ai ka nevojë gjithmonë për ndihmën tuaj që të përfshihet në një aktivitet. Përmes lojrave të tilla fëmija do të zhvillojë jo vetëm aftësit motore, por edhe ato sociale dhe imituese. Një aktivitet interesant është të krijoni një ritëm të caktuar duke përplasur duart në tavolinë ose me njëra- tjetrën, vëreni nëse fëmija juaj shafq ndonjë interes të veçantë ndaj këtij aktiviteti. Nëse po ndihmojeni që edhe ai të kryej të njëjtin aktivitet (Çeça, 2019)

Më poshtë do të listoj tre nga librat më të mirë për fëmijët me sindromë Down dhe lidhjen e tyre me natyrën, benifitet e të mirat e saj, po ashtu nga secili libër do të paraqes një përmblëdhjë të shkurtër se cka më konkret ka shtjelluar autorja në lidhje me tëmën që ne jemi duke diskutuar.

Fëmijët e vegjël me sindromën Down, si të gjithë fëmijët e vegjël, duan të zbulojnë botën e tyre dhe të marrin përvoja të reja. Libri: I can, Can you? (Unë mundem, ti a mundesh? ), është një libër i larmishëm me plotë fotografi me fëmijë me sindromë Down që paraqet gjendjen më të mirë të tyre duke lujatur dhe shjuar të mirat në natyrë... p.sh paraqet ata duke notuar, hanë spageta gjersa shijojnë freskin e ajrit e të qeshur nga gëzimi (Pitzer, 2004).

Ky libër inkurajonë prindërit për afërsi me fëmijët e tyre me sindromë Down. Do të jetë si një 1loj qetësuesi për familjet që tani në familjet e tyre kanë një fëmijë të ri e që ky fëmijë është me sindromë Down. Ky libër në vete përmbanë se ku prindërit mundë të gjejnë qendrat e kujdesit ditor, spitalet, programet për fëmijët e vegjël, praktikat pediatrike etj (Pitzer, 2004) ${ }^{9}$

Libri tjetër, I like Berries, do you? ( Unë pëlqej manaferrat, a i pëlqen edhe ti? ), paraqet fotografi të mrekullueshme të fëmijëve të vegjël me sindromën Doën që shijojnë një përzgjedhje të gjerë të ushqimeve të shëndetshme, nga frutat dhe perimet deri tek mishi dhe ushqimet e lehta. Libri hapet me një pyetje si këngë: Mu më pëlqen brokoli, a të pëlqen edhe ty? dhe kjo thirrje nxitë fëmijët më sindromë Doën të dëshirojnë të provojnë perimen në fjalë... ku ata po ashtu tërhiqen edhe nga ngjyra e era. Ky libër u bë po ashtu për të inkurajuar një dietë të larmishme dhe për të minimizuar cështjet e mundshme ndijore ose orale - motorike që shpesh shoqërohen fëmijët me sindromë Down (Marjorie W. Pitzer, I Like Berries, Do You?, 2013) ${ }^{10}$

\footnotetext{
9 Marjorie W. Pitzer, M.Ed. I Can, Can You? 2004

${ }^{10}$ Marjorie W. Pitzer, M.Ed. I Like Berries, Do You? 2013
} 
Është edhe një libër i titulluar Animal fun for everyone! ( Kafshët argëtim për të gjithë! ), libër i cili tregon fëmijë e vegjël me sindromë Down që kënaqen me një fermë... e si miq të mirëfilltë ata bëjnë kafshësht si: - një qen, mace, kuaj, peshk, rosa dhe më shumë! Po, ashtu paraqet fëmijët duke përqafuar, përkëdhelur, gudulisur dhe ushqyer këto krijesa me gëzof, me pendë dhe me luspa. Cka duhet vequar nga libri, është biseda e një fëmijë me një papagall, ku nga kjo do të shihët se sa të ciltër janë fëmijët me sindromë Down (Marjorie W. Pitzer, Animal Fun for Everyone!, 2014) ${ }^{11}$

\subsection{Sensibilizimi për të mirat mjedisore}

Fjala “ sensibilizim” është një term mjaftë i gjerë, varësisht kontekstit që ne e përdorim. P.sh nga titulli kemi sensibilizimin për të mirat mjedisore, por më konkret përfshihen edhe fëmijët me sindromë Down. Ne, mund të flasim për sensibilizimin mjedisor nga pikëpamja e studiuesve të ndryshëm, por fatëkeqësisht, kur vije puna tek fëmijët me sindromë Down, ky sensibilizim është i paktë ose nuk ka fare. Nga shqyrtimi dhe analiza e materialeve të ndryshme gjatë përgaditjes së punimit të diplomës, nuk është që kam arritur të sigurojë ndonjë analizë të saktë rreth sensibilizimit mjedisor nga fëmijët me sindromë Down, por fatëmirësisht kam arritur të siguroj materiale e analiza të sakta, se loja dhe akivitetet e ndryshme në natyrë, kanë e sjellin benifite të pa numërta për këta fëmijë.

Nisur nga këto dhe puna praktike që unë ushtrojë, tani e 3 vite, në nje organizatë ambientaliste këtu në Prizren, do të vecoja e do të flisja për disa nga aktivitetet që unë kam pasur personalisht me fëmijët me sindromë Down.

Aktiviteti i parë që do të vecoja është për “ Ditë të Tokës” - aktivitet ky që financohet nga komuna e Prizrenit e implementohet cdo vite nga organizata jonë, si lloj aktiviteti vjetor për sensibilizim mjedisor.

Në kuadër të aktivitetit pjësë përfshirëse ishte qendra - Sindromë Down ( Prizren ). Në këtë aktivitet, u mbollen ca fidan nëpërp parqet e qytetit. Femijët me sindromë Down u asistuan në mbjelljen e fidanëve nga unë, por gjithëmonë duke pasur pranë edhe psikologen e qendrës ku këta fëmijë janë të regjistruar.

\footnotetext{
${ }^{11}$ Marjorie W. Pitzer, M.Ed. Animal Fun for Everyone! 2014
} 
Ky aktivitet, ishte shumë dobi sjellës për këta fëmijë edhe pse ndoshta pak e vështirë që nga ata të kuptohet thelbi i thellë i aktivitetit... ata arritën të kuptonin se vendi duhet të jetë i pastër dhe se natyra gëzohet e buzëqesh kur ne mbjellim një fidan. Do të citojë fajlët e Selimit ( fëmijë me sindromë Down, qendra në Prizren ) ... Kam mbjell, kam mbjell një pëmë sot unë... a din Toka është gzu, sikur unë. Kjo fjali e thënë nga zemra është një ndër ndjenjat më të veqanta që si person ndjenë kur punon me këta fëmijë.

\section{Përfundimi}

Gjatë këtij punimi te diplomës u synua të tregohet për disa fusha specifike për fëmijët me sindromë Down. Në rradhe të parë, ku mbi gjithcka se këta fëmijë duhet vlerësuar si të gjithë fëmijët e tjerë, e në rradhë të dytë, se këta fëmijë kanë pavarësi personale, aftësi motorike, edukohen e arsimohen e që lojën e kanë si një ndër gjërat më të dashura për ta, duke mos harruar që përmes saj ata edhe socializohen.

Në këtë punim diplome ka shumë tema e nëntema të shtjelluara, nga më specifiket do të ndaja dy nga ndikuesit më të mëdhenjë për këta fëmijë:

- Prindërit - që njihen si terapistët më të mirë,

- Mësimdhënësit - që nga ky term do të vecoja nëntemën e shqyrtuar "Shkollat nuk duhet të jenë të vecanta!, pasi fëmijët me sindromë Down kanë të drejtën e shkollimit sidomos në shkollat publike, pasi mësimi me fëmijët e tjerë është jetik për arritjen e tyre. Po, ashtu të drejtën që të jenë të barabartë si të gjithë fëmijët e lindur në botë.

Sindroma Down është një temë e cila është pjesë ë secilit vend të botës. Dhe nga tërë diskutimet e cështjet e ngritura, nxitet për përkrahje, afrimitet, dashuri dhe pranim kundrejt fëmijëve si me dhe pa sindromë Down.

\section{Rekomandime}

Nisur nga shqyrtimi i literaturave të ndryshme, rezultatet ngrihen e ulen varësisht vendeve nëpër botë.

\section{Rekomandime për prindër}


- Dallime në asnjë mënyrë, të mos i bëjnë të ndihen si të tepër e të vetmuar e në asnjë mënyrë të parëndësishëm.

- Prindërit nuk duhet në asnjë mënyrë të i izoljnë fëmijët me sindromë Down, pavarësisht a ndodhet në një vend të vogël ( p.sh si tek ne në Kosovë, etj ) apo në një vend të zhvilluar ( SHBA, etj ), përkundrazi duhet që të ju mundësojnë të socializohen me të tjerët.

- Prindërit duhet të ju mundësojnë të jenë pjesë e jetës shkollore dhe të aktiviteteve të shumta, gjë kjo që ju ndihmonë të bëhen të pavarur.

\section{Rekomandime për mësimdhënës}

- Të mos i dallojnë fëmijët me Sindromë Down nga fëmijët e tjerë, të punojnë të gjithë fëmijët së bashku me përkrahje.

- Të jenë të gatshëm të ju ofrojnë ndihmë ne raste kur kanë ngecje gjatë mësimit, si në shkolla publike apo në qendra edukimi dhe të bisedojnë me ta, me dashuri për çdo problem të cilin ata e kanë.

- Bashkëpunimi urëlidhës: mësimdhënës - prindër të jetë në nivelin e duhur dhe të jetë bashkëpunim i ngushtë dhe të bisedohet për të gjitha problemet e fëmijëve, si të vogla ose të medha.

\section{Rekomandime për ministrin e arsimit dhe organizatat përkrahëse}

- MA dhe OJQ -të: Të i kenë më shumë parasysh fëmijët me Sindromën Down, të ju ofrojnë ndihmë në mënyrë që të arrijnë në jetën e tyre, sidomos për pavarësi personale.

- MA : Të ju ofrohen mjetet e duhura të cilat ju ndihmojnë në procesin e mësimit dhe të ju ofrohen kushtet sa më të mira për shkollimin e tyre.

- MA: Të ju mundësohet shkollimi në shkolla të rregullta publike, private së bashku me fëmijët e tjerë dhe pas përfundimit të shkollimit, të kenë edhe këta mundësi punësimi në profesionin që dëshirojnë të punojnë dhe për të cilin janë të aftë, varësisht stadit që ata gjenden.

- MA dhe OJQ -të: Të ju mundësohen udhëtime në vende të cilat ju ndihmojnë në zgjerimin e njohurive të tyre, të ju mundësohen udhëtime brenda shtetit të tyre por edhe jashtë shtetit dhe të hapet një platformë ( lloj i mediave sociale ) për të pasur casje në jetën teknologjike... pasi në shumicën e vendeve në botës ekziston 
një platformë e tillë, ku shumë fëmijë me sindromë Down ndajnë historin e tyre me të gjithë ku me të rast ngritin zërin për barazi e prainm të tyre po, ashtu edhe njohjen me fëmijë të tjerë me sindromë Down.

\section{Referencat}

1. Albania, D. S. (2010). Down Syndrome Albania. Tiranë: SOROS.

2. Angela Glenn, J. C. (2006). Loja dhe të Nxënët në Moshën e Hershme. London: David Fulton Publishers Ltd.

3. B, B. (2012). Biologjia 12. Prishtine: Libri Shkollor.

4. Buckley, S. (2012). Living with Down syndrome. England and Wales: Ebook Edition.

5. Burdette. (2005). Resurrecting free play in young children looking beyond fitness and fatness to attention, affiliation, and. Archives of Paediatrics and Adolescent Medicine.

6. Çeça, M. A. (2019). FËMIJËT dhe LOJA. Tiranë: BashkiaTiranë - Qëndra Ekonomike e Zhvillimit Dhe Edukimit Të Fëmijëve, Sektori i Kujdesit Psiko-social.

7. Cunnigham, C. (2006). Third edition revised and expanded Down Syndrome an introduction for parent and carers. London: Souvenir Press Ltd.

8. Dr.Surekha Ramachadran, 2. (2010).

9. K, R. (2004). Just the Fact Down Syndrome. Chicago.

10. Karen. (2010). Down syndrome: An expectant parents' guide - National Down Syndrome CONGRESS. Atalanta.

11. Karen, T. a. (a.d.). Atalanta, GEORGIA.

12. Karen, T. a. (a.d.). Down syndrome:. Atalanta.

13. Marjorie W. Pitzer, M. (2013). I Like Berries, Do You? Ohio: Woodbine House.

14. Marjorie W. Pitzer, M. (2014). Animal Fun for Everyone! Ohio: Woodbine House.

15. Maynard T, W. J. (2013). 'Moving outdoors: furtherexplorations of "child-initiated" learning in the outdoor.

16. N, Z. (2010). Edukimi Inkluziv. Prishtine.

17. Pitzer, M. W. (2004). I can, can you? Ohio: Woodbine House.

18. Qafleshi, E. (a.d.). Loja dhe të Nxënët në Moshën e Hershme - Një Metodë Gjithëpërfshirëse. Prishtine: Save the Childern, Programi për Shqipërinë. 
19. Ramachadran, D. (2010). The Down's Syndrome handbook. Mumbai.

20. Sharpe, P. (a.d.). The benefits of play for children with down syndrome. Singapor: Institute of Education (Singapore).

21. Todd. (2010). National Down Syndrome CONGRESS. Atlanta.

22. UNESCO. (1960). Konventa E UNESCO-S Kundër Diskriminimit Në Arsim. America. 